\title{
CCR4 Inhibitor FLX475
}

National Cancer Institute

\section{Source}

National Cancer Institute. CCR4 Inhibitor FLX475. NCI Thesaurus. Code C157240.

An orally available, small molecule antagonist of C-C chemokine receptor type 4 (CCR4) with potential immunomodulatory and antineoplastic activities. Upon oral administration, FLX475 inhibits the binding of CCR4 to its signaling molecules, thereby blocking the recruitment of regulatory T-cells (Tregs) to the tumor microenvironment (TME). This may abrogate the immunosuppressive effects of Tregs and promote an effective antitumor immune response. CCR4, a chemokine receptor normally expressed on circulating and tissue-resident T-cells, is highly expressed on circulating Tregs and is associated with poor prognosis in certain cancers. 